\title{
Nacre-like alumina composites reinforced by zirconia particles
}

\author{
Ronan Henry ${ }^{a}$, Hassan Saad ${ }^{b}$, Sandrine Dankic-Cottrino ${ }^{a}$, Sylvain Deville ${ }^{c}$, Sylvain Meille ${ }^{\text {* }}$ \\ a INSA Lyon, UCBL, CNRS, MATEIS, UMR 5510, 7 avenue Jean Capelle, 69621 Villeurbanne, France \\ ${ }^{\mathrm{b}}$ Laboratoire de Synthèse et Fonctionnalisation des Céramiques, UMR 3080 CNRS/Saint-Gobain, Saint-Gobain \\ Research Provence, Cavaillon, France \\ ' Université de Lyon, Université Claude Bernard Lyon 1, CNRS, Institut Lumière Matière, 69622 Villeurbanne, \\ France \\ * Corresponding author: sylvain.meille@insa-lyon.fr
}

\section{Keywords}

Bio-inspiration, nacre, alumina, zirconia, field assisted sintering (FAST), mechanical fracture properties, composites

\begin{abstract}
Nacre-like alumina is a class of bio-inspired ceramic composite manufactured by field-assisted sintering of green bodies made primarily of alumina platelets with an anisotropic microstructure. Here we investigate the addition of zirconia particles to enhance the mechanical properties of the composite. The resulting structure is a nacrelike anisotropic structure which features deflection and reinforcement during crack propagation. Monoclinic zirconia has no impact on the mechanical properties of the composite while tetragonal zirconia improves its fracture resistance properties. Both types of zirconia seem to slow down grain growth during sintering. The addition of zirconia stabilised in the tetragonal phase is thus a good option to obtain a composite with a fine microstructure and higher mechanical properties than a standard nacre-like alumina, with a flexural strength of $626 \pm 39 \mathrm{MPa}$ and a crack initiation toughness of $6.1 \pm 0.6 \mathrm{MPa} \cdot \mathrm{m}^{0.5}$.
\end{abstract}

\section{Introduction}

Ceramics are usually brittle materials, i.e. with very little deformation before fracture. Although ceramics are often used for their chemical inertia, high rigidity, and functional properties at high temperature, their use is largely limited due to their brittle behaviour, especially for structural applications [1]. Alumina is one of the most commonly used technical ceramic in industrial applications. It can be reinforced with zirconia resulting in composites commonly called Zirconia-Toughened Alumina (ZTA) which are characterized by higher mechanical properties than conventional alumina [2][3]. The use of a stabilizer, such as yttria, retains zirconia in the tetragonal phase after sintering at room temperature. Another way to stabilize zirconia is to use a narrow size distribution of zirconia particles dispersed in an alumina matrix [4], for example through a colloidal processing route [5]. When a crack propagates in the material, the stress field at the crack tip causes a tetragonal to monoclinic phase transformation of the zirconia particles. The volume increase resulting from this phase transformation generates a compressive field around the crack tip, locally slowing down the crack propagation and macroscopically increasing the toughness of the material [6].

The replication of some of the microstructural features encountered in natural composite is another approach to improve the resistance to crack propagation of ceramics [7]. Nacre is a natural material encountered in many seashells' species. It is mainly composed of brittle elements ( $95 \mathrm{vol} . \%$ aragonite and $5 \mathrm{vol} . \%$ organic material) but is characterized by a non-catastrophic failure once the fracture has been initiated. It shows a singular brick-andmortar hierarchical microstructure, with aragonite platelets (of around $10 \mu \mathrm{m}$ in diameter and $500 \mathrm{~nm}$ in thickness) and a polymeric secondary phase between the platelets. This highly anisotropic microstructure leads to crack deflection and energy dissipation during the fracture and leads to macroscopic fracture properties much higher than the properties of its constituents [8]. Many strategies have been reported to obtain materials with brick and mortar microstructures, using different types of bricks $\left(\mathrm{Al}_{2} \mathrm{O}_{3}\right.$, glass, SiC...), different compositions of the mortar (polymer, metal, glass...), as well as a variety of processing routes (tape casting, layer by layer deposition, ice templating, magnetically assisted slip casting, sedimentation) [9]. 
Because it uses only mineral components, one of these compositions made of alumina platelets as bricks and a refractory phase as mortar [10], is particularly attractive. Materials obtained using this approach are referred to as nacre-like alumina. In addition to an increase of the resistance to crack propagation, nacre-like alumina materials exhibit, similarly to usual ceramics, high rigidity, high hardness and a good resistance to corrosion and temperature. These composites are obtained by densifying a green body composed of aligned platelets and mortar phase precursors. Several approaches have been proposed to achieve this alignment, including icetemplating or magnetic field assisted slip casting. A simpler approach was recently presented, is based on fieldassisted sintering (FAST) and is able to align and densify the material in a single process [11][12]. FAST makes it possible to obtain nacre-like microstructures with a good alignment of the platelets [12] and thus mechanical properties similar to that reported previously.

Most of the work on nacre-like alumina so far has focused on its processing and characterization, and relatively little on improving its properties. Yet, numerical modelling has shown that the mechanical properties could be further improved by increasing the strength of its constituents [13], and particularly the strength of the secondary phase, which is the weakest point of the structure [14]. Moreover, some authors have succeeded using a secondary phase composed of aluminium borate instead of the silica-based phase used previously, improving the strength and the toughness of the nacre-like alumina, while maintaining the refractory properties of the material [15].

Here we investigate the possibility of adding zirconia to nacre-like alumina in order to improve its mechanical properties, work which follows a feasibility study carried out in a PhD thesis [16]. Zirconia micro-platelets are not commercially available, we thus focus here on using zirconia particles to reinforce a nacre-like alumina made of alumina platelets. The challenge is to disperse homogeneously the zirconia particles at the interface of alumina platelets, while preserving the anisotropic and oriented structure of the nacre-like alumina. We investigate several strategies for the addition of zirconia, using either zirconia precursors or zirconia particles.

\section{Materials and method}

\subsection{Compositions}

Seven types of nacre-like composites were prepared (TABLE 1): six samples were prepared with a sintering cycle with a maximum uniaxial pressure of $40 \mathrm{MPa}$, one sample (labelled HP for High Pressure) was sintered at a maximum uniaxial pressure of $80 \mathrm{MPa}$. Six different compositions were tested, whose slurries are schematically represented in FIGURE 1. 


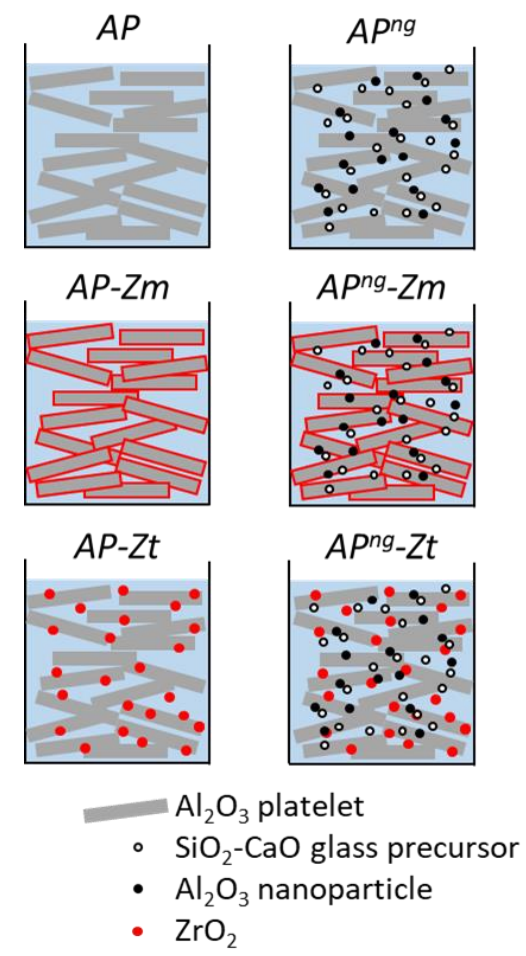

Figure 1 : Schematic illustration of the different slurries prepared in water for the preparation of the different samples tested in this study. (C) (2021) R. Henry et al. (10.6084/m9.figshare.14994159) CC BY 4.0 license https://creativecommons.org/licenses/by/4.0/.

- $\quad \boldsymbol{A P}$ (Alumina Platelets): only alumina platelets were sintered without secondary phase.

- $\quad \boldsymbol{A P}$-Zm (Alumina Platelets - monoclinic Zirconia): un-stabilized zirconia was added to the platelets by a colloidal process route before being sintered without secondary phase.

- $\quad \boldsymbol{A P}$-Zt (Alumina Platelets - tetragonal Zirconia): zirconia stabilized in tetragonal-phase was added to the alumina platelets by powder mixing and sintered without secondary phase.

- $\quad \boldsymbol{A P}^{n g}$ (Alumina Platelets, nanoparticles and glass): alumina platelets were sintered with alumina nanoparticles and a secondary phase composed of $\mathrm{SiO}_{2}-\mathrm{CaO}$ glass.

- $\quad \boldsymbol{A} \boldsymbol{P}^{n g}$-Zm (Alumina Platelets, nanoparticles and glass - monoclinic Zirconia): un-stabilized zirconia was added to the platelets by a colloidal process route before being sintered with alumina nanoparticles and a secondary phase of $\mathrm{SiO}_{2}-\mathrm{CaO}$ glass.

- $\quad \boldsymbol{A} \boldsymbol{P}^{n g}$-Zt (Alumina Platelets, nanoparticles and glass - tetragonal Zirconia): zirconia stabilized in tetragonal-phase was added to the alumina platelets by powder mixing and sintered with alumina nanoparticles and a secondary phase of $\mathrm{SiO}_{2}-\mathrm{CaO}$ glass.

Table 1 : Composition, sintering conditions and relative density after FAST of the composite samples.

\begin{tabular}{|c|c|c|c|c|c|c|}
\hline Sample & Platelets & Nanoparticles & Secondary phase & Particles & $\begin{array}{c}\text { Sintering } \\
\text { pressure }(\mathrm{MPa})\end{array}$ & $\begin{array}{c}\text { Relative } \\
\text { density (\%) }\end{array}$ \\
\hline$A P$ & $\mathrm{Al}_{2} \mathrm{O}_{3}$ & - & - & - & 40 & $95 \%$ \\
\hline$A P-Z m$ & $\mathrm{Al}_{2} \mathrm{O}_{3}$ & - & - & $\mathrm{ZrO}_{2}$ & 40 & $92 \%$ \\
\hline$A P-Z t$ & $\mathrm{Al}_{2} \mathrm{O}_{3}$ & - & - & $3 \mathrm{Y}-\mathrm{ZrO}_{2}$ & 40 & $92 \%$ \\
\hline$A P-Z t-H P$ & $\mathrm{Al}_{2} \mathrm{O}_{3}$ & - & - & $3 \mathrm{Y}-\mathrm{ZrO} 2$ & 80 & $97 \%$ \\
\hline$A P^{n g}$ & $\mathrm{Al}_{2} \mathrm{O}_{3}$ & $\mathrm{Al}_{2} \mathrm{O}_{3}$ & $\mathrm{SiO}_{2}-\mathrm{CaO}$ & - & 40 & $97 \%$ \\
\hline$A P^{n g}-Z m$ & $\mathrm{Al}_{2} \mathrm{O}_{3}$ & $\mathrm{Al}_{2} \mathrm{O}_{3}$ & $\mathrm{SiO}_{2}-\mathrm{CaO}$ & $\mathrm{ZrO}_{2}$ & 40 & $96 \%$ \\
\hline$A P^{n g}-Z t$ & $\mathrm{Al}_{2} \mathrm{O}_{3}$ & $\mathrm{Al}_{2} \mathrm{O}_{3}$ & $\mathrm{SiO}_{2}-\mathrm{CaO}$ & $3 \mathrm{Y}-\mathrm{ZrO}_{2}$ & 40 & $97 \%$ \\
\hline
\end{tabular}




\subsection{Powder preparation}

All powders were prepared from micrometer-sized alumina platelets (Ronaflair White Sapphire, Merck). When the composition contains alumina nanoparticles and glass ( $A P^{n g}$ samples), the composite contains 95 vol.\% platelets, 3.5 vol.\% alumina nanoparticles and 1.5 vol.\% glass (( $\left.\mathrm{SiO}_{2}: \mathrm{CaO}\right)$ molar composition of $(75: 25)$ as in [12]). When the composition contains zirconia particles ( $Z m$ and $Z t$ samples), the zirconia content represents 15 wt.\%, (i.e. 10 vol.\%) of the platelets.

The powders of the $A P^{n g}$ compositions containing alumina nanoparticles and glass precursors $\left(\mathrm{SiO}_{2}, \mathrm{CaO}\right)$, were prepared to adsorb these nanoparticles on the platelet surface. Alumina nanoparticles $\mathrm{Al}_{2} \mathrm{O}_{3}$ (TMDAR, TaiMei), calcium carbonate $\mathrm{CaCO}_{3}$ (Sigma Aldrich) and the colloidal silica $\mathrm{SiO}_{2}$ (Nexsil20K30, Nyacol) were first dispersed in deionized water in the presence of a dispersant (Darvan 7NS, Vanderbilt Minerals LLC) and stirred for 15 minutes. The slurry was then mixed with alumina milling media for 20 hours. Platelets were added for the last three hours only to avoid any excessive breaking. After removing the alumina milling media, the suspension was soaked in liquid nitrogen until completely frozen and then freeze-dried for about 48 hours to remove all water. After this step, a solid cake is obtained, which is de-agglomerated manually with mortar and filtered with a coarse sieve. The powder obtained is finally heat treated for 1 hour at $900^{\circ} \mathrm{C}$ to remove all traces of organic compounds and to start the decomposition of calcium carbonate $\mathrm{CaCO}_{3}$ to calcium oxide $\mathrm{CaO}$.

The powder of the $Z m$ compositions were prepared by depositing a layer of unstabilized zirconia on the surface of the alumina platelets by the alkoxide process route [5]. The alumina platelets were first dispersed in absolute ethanol. A zirconia precursor solution (Zirconium(IV) propoxide, 70\% in 1-propanol, Sigma-Arldrich) is diluted in absolute ethanol ( 66.7 vol\% solution, 33.3\% absolute ethanol). The resulting solution was added dropwise to the solution under stirring and containing the platelets. Once all the propoxide has been added, the solution (still under stirring) is heated to $70^{\circ} \mathrm{C}$ in order to evaporate the ethanol for about 8 hours and finally in the oven at $100^{\circ} \mathrm{C}$ for one night to remove all traces of ethanol. A paste was obtained, which was de-agglomerated and filtered with mortar and filtered with a coarse sieve. Finally, the powder was heat-treated at $850^{\circ} \mathrm{C}$ for 2 hours.

The platelets of the $Z t$ compositions were obtained from an adsorption of zirconia nanopowders partially stabilized in the tetragonal phase by 3 molar \% yttrium (TZ-3Y-E, TOSOH) on the alumina platelets. In the case of the $A P^{n g}-Z t$ composition, the zirconia powder was added to the solution containing the alumina nano-particles and the precursors of the glass phase. For the $A P-Z t$ powder, the zirconia powder was placed in water with a dispersant (Darvan 7NS, Vanderbilt Minerals LLC) under stirring for $15 \mathrm{~min}$. The alumina platelets were then added to the solution and mixed for three hours with alumina media. Afterwards, the process is the same as for $A P^{n g}$, i.e. freezing in liquid nitrogen followed by freeze-drying, heat treatment and de-agglomeration of the powder.

\subsection{Densification process}

In this work, the preferential orientation of the platelets does not come from a pre-alignment step (using ice templating or magnetically assisted slip casting), but is done in a single step in parallel with the sintering of the powder [12]. In order to maintain a fine microstructure, we used field assisted sintering (FAST) (HPD25, FCT SystemeGmbH, Germany), which allows us to combine rapid heating with uniaxial pressure of the platelets. This uniaxial pressure applied to the powder aligns the platelets: the longest dimension of the platelets (in their basal plane) is thus aligned perpendicularly to the compression axis of the powder.

Each powder was placed in a graphite die (30 $\mathrm{mm}$ inner diameter) lined with a graphite foil $(0.35 \mathrm{~mm}$ thick) and sintered under vacuum. The sintering cycle, optimized in previous work [10], was applied to all the compositions. This cycle consists in heating up to $1450^{\circ} \mathrm{C}$ at a speed of $100^{\circ} \mathrm{C} / \mathrm{min}$ and under a pressure of $20 \mathrm{MPa}$, then applying a dwell time of $15 \mathrm{~min}$ at $1450^{\circ} \mathrm{C}$ and under a pressure of $40 \mathrm{MPa}$ or $80 \mathrm{MPa}$ (hereafter referred as $\mathrm{HP}$ sample). Finally, the sample was cooled at $100^{\circ} \mathrm{C} / \mathrm{min}$ down to room temperature. The pellets obtained have a diameter of $30 \mathrm{~mm}$ and a thickness of about $4-5 \mathrm{~mm}$. 


\subsection{Material characterization}

The final density of every sample was evaluated using an Archimedes' method and is presented as the relative density compared to the theoretical density of the material (TABLE 1) with the density of alumina taken as $3.97 \mathrm{~g} . \mathrm{cm}^{-3}$ and zirconia as $5.68 \mathrm{~g} . \mathrm{cm}^{-3}$.

Every sintered disk was cut with a micro-slicer in order to obtain samples with millimetre dimensions and with its length along the preferential direction of the platelets. The surfaces were then polished with diamond paste from $9 \mu \mathrm{m}$ down to $1 \mu \mathrm{m}$ followed by a vibratory polishing step with colloidal silica suspension of $0.03 \mu \mathrm{m}$. Then, mirror-polished surfaces were imaged by Scanning Electron Microscopy (SEM) (SUPRA 55, Zeiss) with a low acceleration voltage of $1 \mathrm{kV}$.

X-ray Diffraction (XRD) analysis were performed using a D8 advance Diffractometer (Bruker) with a scan speed of $1^{\circ} \mathrm{min}^{-1}$ and a step size of $0.01^{\circ}$ on unpolished disk surfaces for $2 \theta$ angles between $27^{\circ}$ and $33^{\circ}$ in order to detect the presence of the different phase of zirconia [17] ( $m:$ monoclinic and $t$ : tetragonal).

\subsection{Mechanical testing}

The mechanical tests were all carried out in bending using rectangular non-chamfered beams of dimensions $W$ (thickness), $B$ (width) and $L$ (length) cut from the sintered pellets. All tests were performed with an electromechanical testing machine (Instron 8562, High Wycombe UK) in four-points bending with a support span of $12 \mathrm{~mm}$ and a loading span of $3 \mathrm{~mm}$. The specimens were loaded in the direction perpendicular to the orientation of the platelets with a constant displacement rate. The deflection of the beam was measured using a linear variable differential transform (LVDT) sensor. For each sample and type of test, different tests were performed (between 2 and 8), and their number is given together with the results FIGURE 4.

The fracture strength $\sigma_{R}$ of the materials was measured on beams having all the same dimensions of $W=2 \mathrm{~mm}$, $B=2 \mathrm{~mm}$ and $L=15 \mathrm{~mm}\left(2 \times 2 \times 15 \mathrm{~mm}^{3}\right.$ geometry $)$ in order to be able to compare the strength between them without any fracture probabilistic effect. The surfaces in contact with the spans have been mirror-polished. The samples were monotonically loaded at a constant displacement rate of $50 \mu \mathrm{m} / \mathrm{min}$, and the strength was calculated by linear-elastic relationships by taking the maximum load measured during the test.

The crack propagation resistance of the materials was measured on notched specimens with a thickness $W$ ranging from $3.5 \mathrm{~mm}$ to $5 \mathrm{~mm}$ depending on the height of the sintered disc. The ratio of the notch depth on the specimen height $a / W$ was set to 0.4 . The notches were made in two steps, first a pre-notch was prepared with a diamond saw with a thickness of $300 \mu \mathrm{m}$. Then, this notch was refined with a razor blade and a diamond paste containing $1 \mu \mathrm{m}$ particles in order to have a notch tip radius with a curvature of about $20 \mu \mathrm{m}$. The loading was done at a constant displacement rate of $10 \mu \mathrm{m} / \mathrm{min}$. The stress intensity factor $K_{\lrcorner}$was determined during stable crack using the J-integral method exposed in ASTM-E1820 standard [18]. Crack length $\Delta a$ were indirectly determined by the method of mechanical compliance, described for example in [12], which allows the calculation of an equivalent crack length by projecting the actual crack length on the axis of the notch. This method, although approximate in our case because there is significant crack deviation, allows the calculation of the initiation toughness $K_{J}^{0}$, a parameter which is not affected by sample size effect [12]. This allows to compare these results with other publications that have used this method [10][15].

\section{Results}

\subsection{X-ray diffraction}

X-ray diffraction shows that the nature of the zirconia phase depends on the composite processing (FIGURE 2). The $A P$ and $A P^{n g}$ zirconia-free samples do not show any peak on the XRD spectra for $2 \theta$ between $27^{\circ}$ and $33^{\circ}$. For the $Z m$ compositions, there are two significant peaks for $2 \theta=28.3^{\circ}$ and $2 \theta=31.5^{\circ}$, which correspond respectively to the (111) and (111) peaks of monoclinic zirconia [17]. A secondary peak can also be noted for $A P^{n g}-Z m$ composition for $2 \theta=31.5^{\circ}$ which corresponds to the (101) peak of tetragonal zirconia [17]. The Zt samples shows a main peak for $2 \theta=31.5^{\circ}$, i.e. characteristic of the tetragonal zirconia. The $A P$ - Zt sample shows secondary peaks corresponding to monoclinic zirconia while the $A P-Z t-H P$ and the $A P^{n g}-Z t$ sample do not show any secondary peak or very small secondary peaks. 


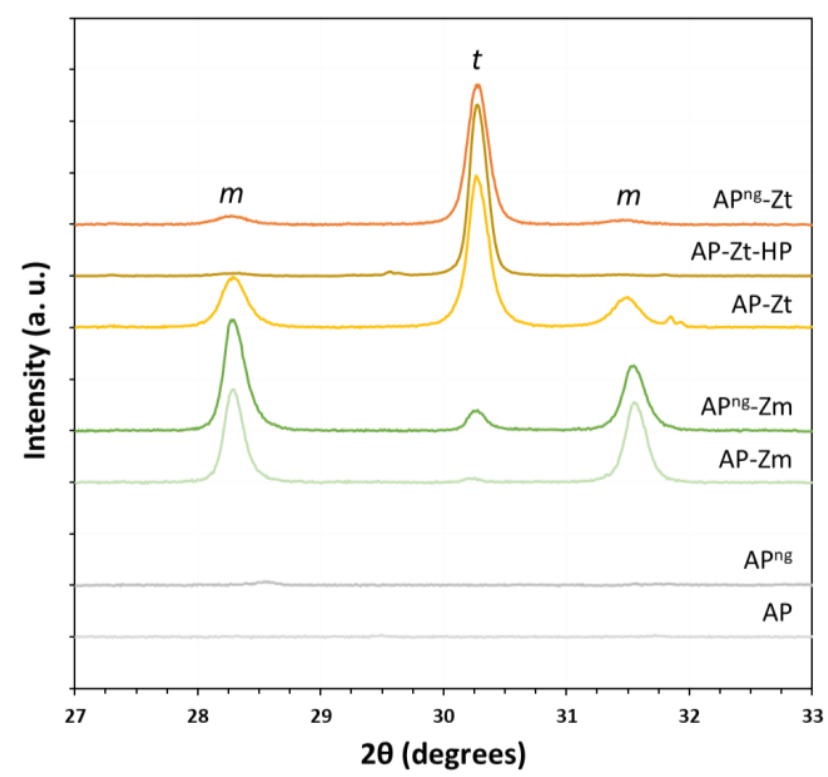

Figure 2 : XRD spectra of the samples. (c) (2021) R. Henry et al. (10.6084/m9.figshare.14994159) CC BY 4.0 license https://creativecommons.org/licenses/by/4.0/.

\subsection{Mechanical characterization}

The force-displacement curves of all notched bending tests show a similar trend (FIGURE 3). First, there is a linear phase where the material deforms elastically. It is followed by a non-linear behaviour, where the load continues to increase with the displacement, but with a more irregular curve, sometimes with sudden small drops in load; this is due to the stable propagation of a crack in the specimen. Then the specimens break completely. $A P^{n g}$ compositions, with glass phase and alumina nanoparticles, seem to show a longer nonlinear phase. The curves in FIGURE 3 have been normalized in load and displacement from the point where the curve leaves the elastic regime. Finally, these curves show that each sample presents reinforcement during crack propagation, a typical behaviour of nacre-like aluminas.

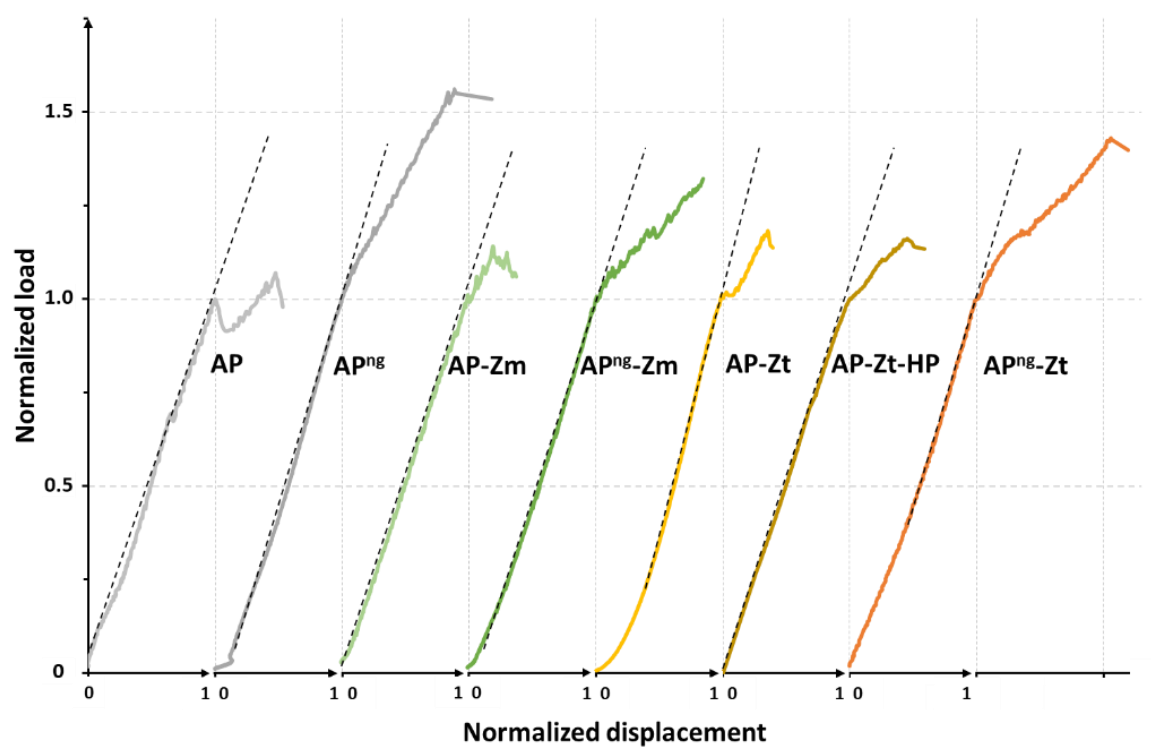

Figure 3 : Load-displacement curves normalized by the load and deflection at the point where the crack propagation begins (corresponding to the apparition of non-linearity). (c) (2021) R. Henry et al. (10.6084/m9.figshare.14994159) CC BY 4.0 license https://creativecommons.org/licenses/by/4.0/.

Fracture properties, strength and toughness at initiation, vary greatly with the composition but also with the sintering cycle (FIGURE 4). For samples prepared with a standard sintering cycle (maximum pressure of $40 \mathrm{MPa}$ ), 
the properties are better for $A P^{n g}$ compositions containing glass phase and alumina nanoparticules than for $A P$ compositions. The zirconia-free sample $A P$ and the sample with monoclinic zirconia $A P-Z m$ have similar properties, i.e. an initation toughness of $3.7 \pm 0.3 \mathrm{MPa}^{0.5}$ and $3.2 \pm 0.3 \mathrm{MPa} . \mathrm{m}^{0.5}$, respectively, and a low strength of $144 \pm 14 \mathrm{MPa}$ and $85 \pm 4 \mathrm{MPa}$, respectively. The AP-Zt specimen, although without glass phase and with the same sintering cycle, show higher properties with a $K_{J}^{0}$ of $5.5 \pm 0.8 \mathrm{MPa} \cdot \mathrm{m}^{0.5}$ and a strength of $230 \pm$ $62 \mathrm{MPa}$. The AP-Zt-HP specimen, with the same composition as AP-Zt but sintered at a higher maximum pressure of $80 \mathrm{MPa}$, has higher properties, with a $K_{\jmath}^{0}$ of $6.6 \pm 1.0 \mathrm{MPa} \cdot \mathrm{m}^{0.5}$ and a strength of $367 \pm 55 \mathrm{MPa}$. For compositions with glass phase and alumina nano-particles, the zirconia-free sample $A P^{n g}$ and the sample with monoclinic zirconia $A P^{n g}-\mathrm{Zm}$ have also similar properties; a $K_{\rho}^{0}$ of $6.4 \pm 0.2 \mathrm{MPa} \cdot \mathrm{m}^{0.5}$ and $6.1 \pm 0.6 \mathrm{MPa} \cdot \mathrm{m}^{0.5}$, respectively, and a strength of $422 \pm 48 \mathrm{MPa}$ and $415 \pm 29 \mathrm{MPa}$, respectively. When tetragonal zirconia is present $\left(A P^{n g}-Z t\right)$, the initation toughness is slightly lower, about $5.5 \pm 0.8 \mathrm{MPa} \cdot \mathrm{m}^{0.5}$, but the strength is $626 \pm 39 \mathrm{MPa}$, i.e. about $50 \%$ higher.

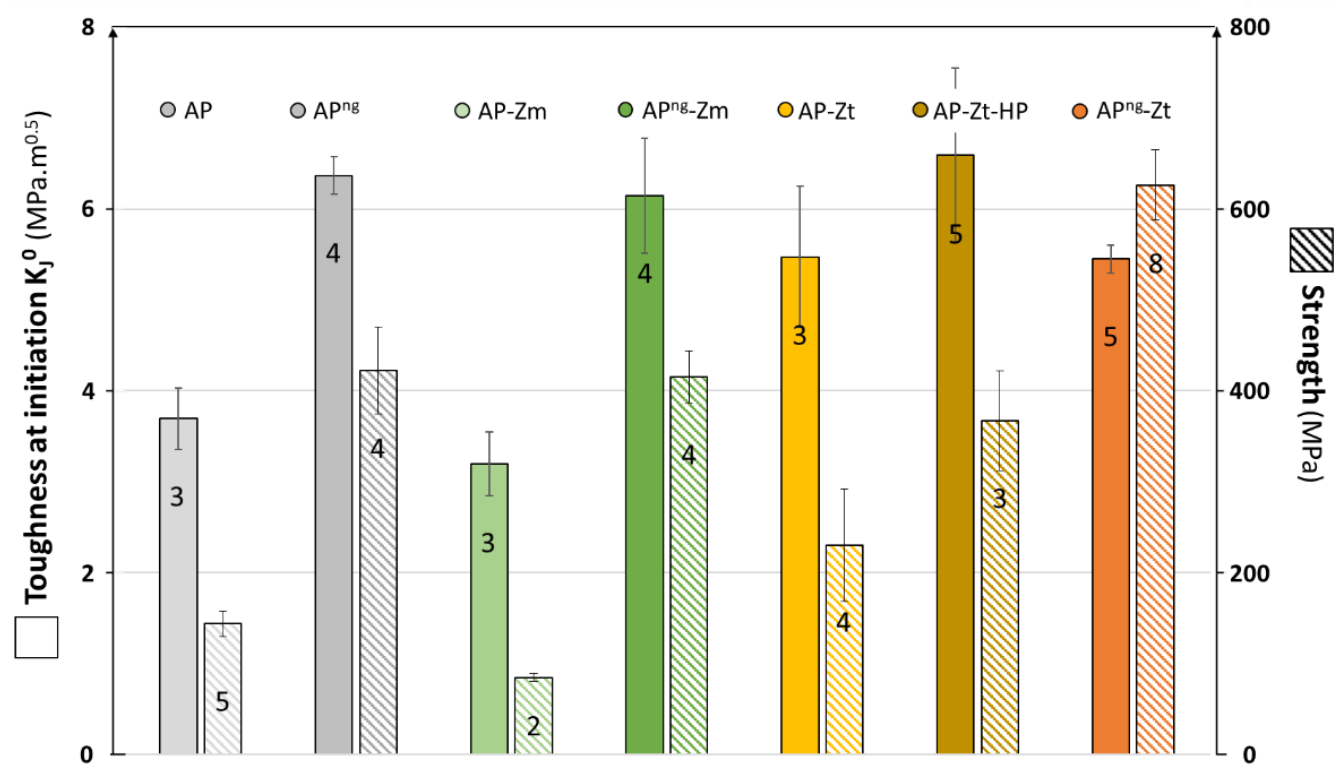

Figure 4 : Fracture toughness at crack initiation and flexural strength of every tested specimen; the number of tested samples is given in each bar. (C) (2021) R. Henry et al. (10.6084/m9.figshare.14994159) CC BY 4.0 license https://creativecommons.org/licenses/by/4.0/.

These differences in mechanical properties could be explained by different factors, in particular the differences in density between the samples, but also their microstructure. First of all, the sample relative densities of $A P, A P$ $Z m$ and $A P-Z t$, around $93 \%$, are clearly below the relative densities of $A P^{n g}, A P^{n g}-Z m$ and $A P^{n g}-Z t$, around $99 \%$ (TABLE 1). For $A P^{n g}$ compositions, the alumina nanoparticles and the glass phase help the densification of the material. Moreover, when a higher pressure is applied during sintering of the sample without nanoparticles and glass phase, it shows the same relative density of composition with glass phase ( $99 \%$ for $A P-Z t-H P)$, the increase in pressure improving the densification as compared to AP-Zt (TABLE 1).

\section{3. $\quad$ Sintering curves}

The sintering curves for the standard cycle (FIGURE 5), i.e. a dwell time at $1450^{\circ} \mathrm{C}$ for 15 min with a pressure of $40 \mathrm{MPa}$, show relatively little difference between samples without glass phase. In presence of a glass phase, the densification rate peak seems more pronounced around $1300^{\circ} \mathrm{C}$ (i.e. for a time of $500 \mathrm{~s}$ in FIGURE 5), and when both zirconia and a glass phase are present $\left(A P^{n g}-Z m\right.$ and $\left.A P^{n g}-Z t\right)$, densification starts slightly earlier than for other samples. 

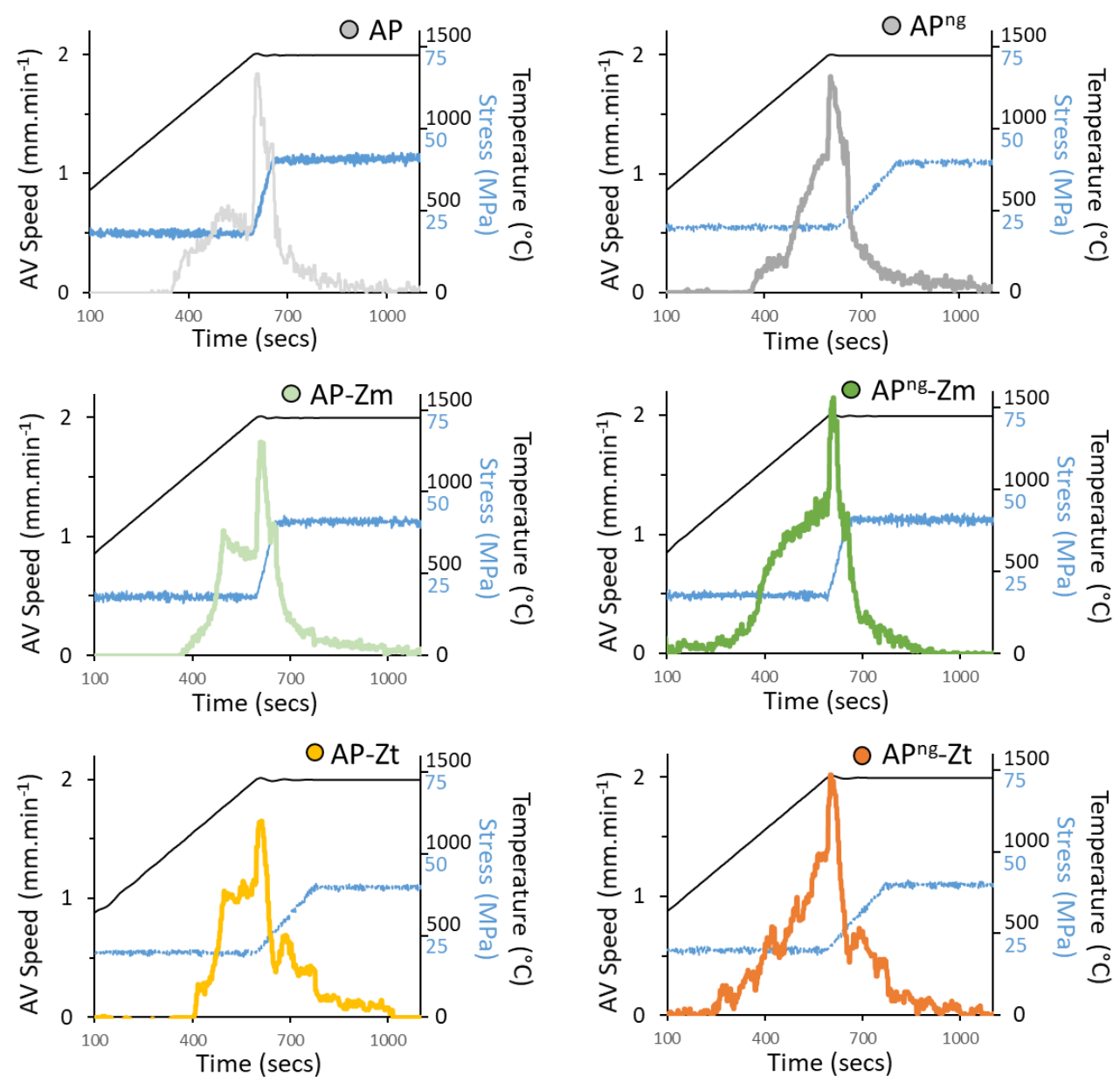

Figure 5 : Densification curves for the standard sintering cycle, left column, composition without glass phase and alumina nanoparticles, right column compositions with glass phase and alumina nanoparticles. Top line: composition without zirconia, middle line: compositions with monoclinic zirconia, bottom line: composition with tetragonal zirconia. (C) (2021) R. Henry et al. (10.6084/m9.figshare.14994159) CC BY 4.0 license https://creativecommons.org/licenses/by/4.0/.

\subsection{Micrographs}

The final platelet size appears to be little affected by the FAST process with the standard sintering cycle (FIGURE 6). The microstructure remains fine for all samples; only the AP sample appears to have larger platelets than the other samples. For samples with zirconia addition, zirconia appears as particles clustered at the grain boundaries between the alumina platelets, especially at the triple grain boundaries. The distribution is rather homogeneous in the material with particles ranging from a few hundred nanometers to a few microns in diameter. Interestingly, all the samples retain their anisotropic texture with the addition of zirconia, with zirconia particles showing an elongated shape, with the shortest dimension along the compression axis of the FAST. 


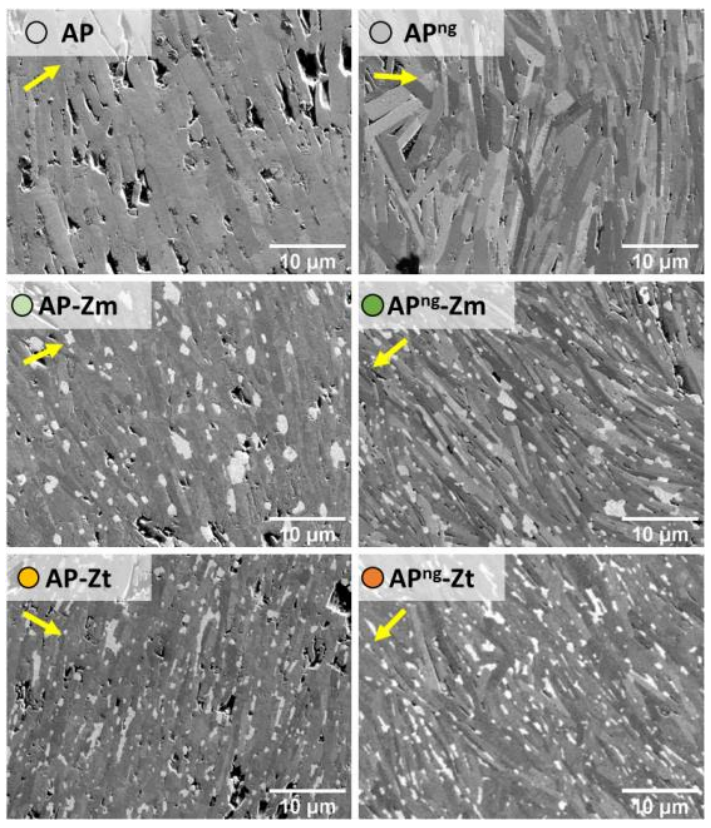

Figure 6 : SEM micrograph of the different samples prepared with a standard FAST cycle. The arrows show the axis of the compression applied during sintering. $\mathrm{ZrO}_{2}$ appears in light grey. () (2021) R. Henry et al. (10.6084/m9.figshare.14994159) CC BY 4.0 license https://creativecommons.org/licenses/by/4.0/.

\subsection{Characterization of crack deflection}

The force-displacement curves (FIGURE 3) show the presence of reinforcement during a stable crack propagation. The cracks observed after testing on notched specimens (FIGURE 7) show a strong deviation from the axis of the notch. There is no obvious relationship between the overall path of the cracks and the initiation toughness (FIGURE 4). Indeed, as an example, the AP sample has a lower $K_{\rho}^{0}$ than the other compositions and however shows a crack deviation similar to the other samples.
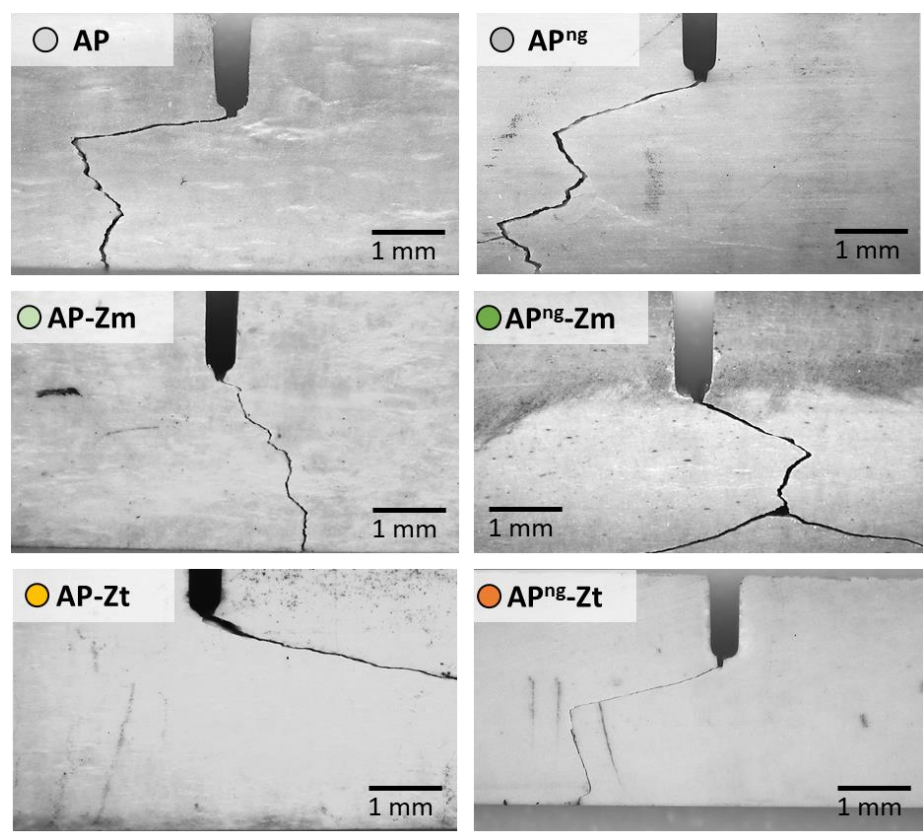

Figure 7 : Optical micrographs of cracks after SENB tests for samples prepared with a standard FAST cycle. The initial notch is visible in the middle of the sample, top face. () (2021) R. Henry et al. (10.6084/m9.figshare.14994159) CC BY 4.0 license https://creativecommons.org/licenses/by/4.0/.

The structure of the grain boundaries varies between the different samples depending on the presence or on the absence of zirconia particles, glass phase, and alumina nanoparticles. As cracks propagate along the interfaces, 
one would expect a difference in crack propagation behaviour between the samples. Since the shape of the cracks does not vary much and since the $K_{\lrcorner}^{0}$ is only representative of the beginning of propagation, the study of the R-curves, i.e. the evolution of toughness with the crack depth (FIGURE 8), is of interest. A size effect in crack resistance curves has been clearly noted [12]. In this paper, R-curves are mainly used for comparison purposes, on similar samples tested in the same loading conditions. Thus, this work does not intend to discuss the shape of $\mathrm{R}$-curves or the toughness values after crack propagation (discussions on this aspect can be found in the literature [10][12]). R-curves are plotted only at the beginning of crack propagation $(0.3 \mathrm{~mm}$, one quarter of the ligament length) in order to compare the different compositions.

All R-curves are linear with $\Delta a$ in the range studied, but their slopes vary between the compositions. $A P$ and $A P$ $Z m$ have a slope ranging from $12.10^{3}$ to $15.10^{3} \mathrm{MPa} \cdot \mathrm{m}^{-0.5}, A P-Z t, A P^{n g}-Z m$ and $A P^{n g}-Z t$ around $20.10^{3} \mathrm{MPa}^{-0.5}$ and finally $A P^{n g}$ around $30.10^{3} \mathrm{MPa} \cdot \mathrm{m}^{-0.5}$.
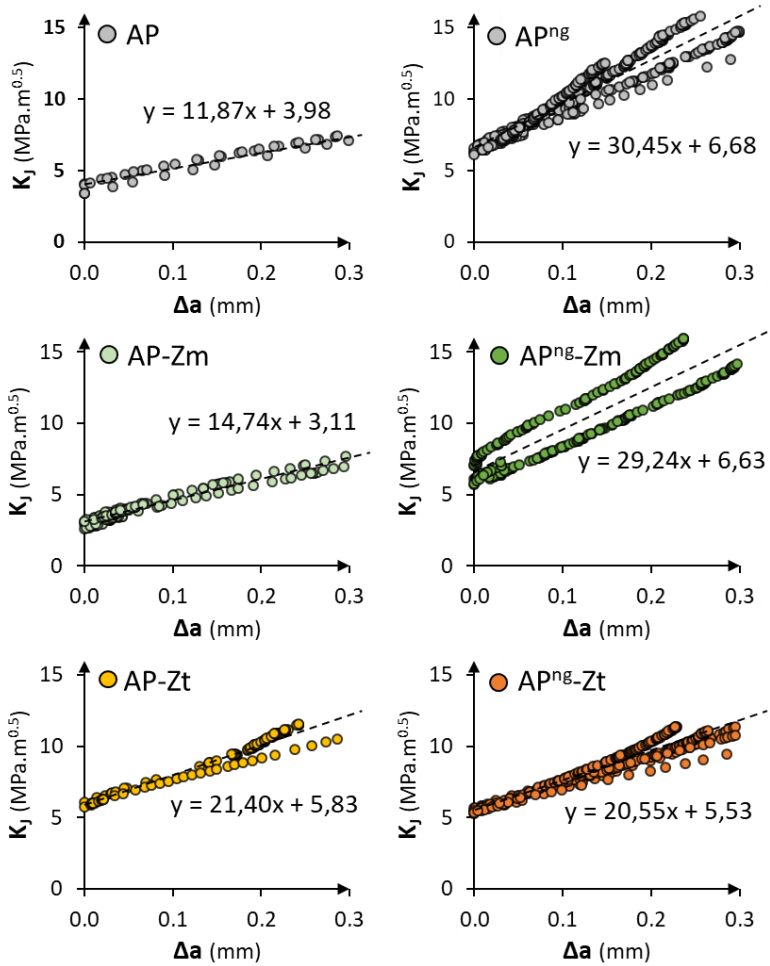

Figure 8 : $R$-curves for samples prepared with a standard FAST cycle, for $\Delta a$ up to $0.3 \mathrm{~mm}$, corresponding to the ASTM limit $\left(d a=0.25\left(W-a_{0}\right)\right)$. (c) (2021) R. Henry et al. (10.6084/m9.figshare.14994159) CC BY 4.0 license https://creativecommons.org/licenses/by/4.0/.

\subsection{High pressure sintered sample}

In the case of the AP-Zt-HP sample, without glass phase but sintered with a maximum pressure of $80 \mathrm{MPa}$, the sintering behaviour is similar to $A P^{n g}$, a sample sintered at $40 \mathrm{MPa}$ with glass phase (FIGURE 9). The densification curve shows a pronounced bump, showing better densification than the other samples without glass phase, illustrated by a higher relative density after sintering (99\%) (TABLE 1). The microstructure is also very similar, with a homogeneous distribution of zirconia particles, a good platelet orientation and no apparent grain growth. Crack deviation is clearly noted and R-curves have an average slope around $20.10^{3} \mathrm{MPa} \cdot \mathrm{m}^{-0.5}$, just like the other samples with tetragonal zirconia particles. 

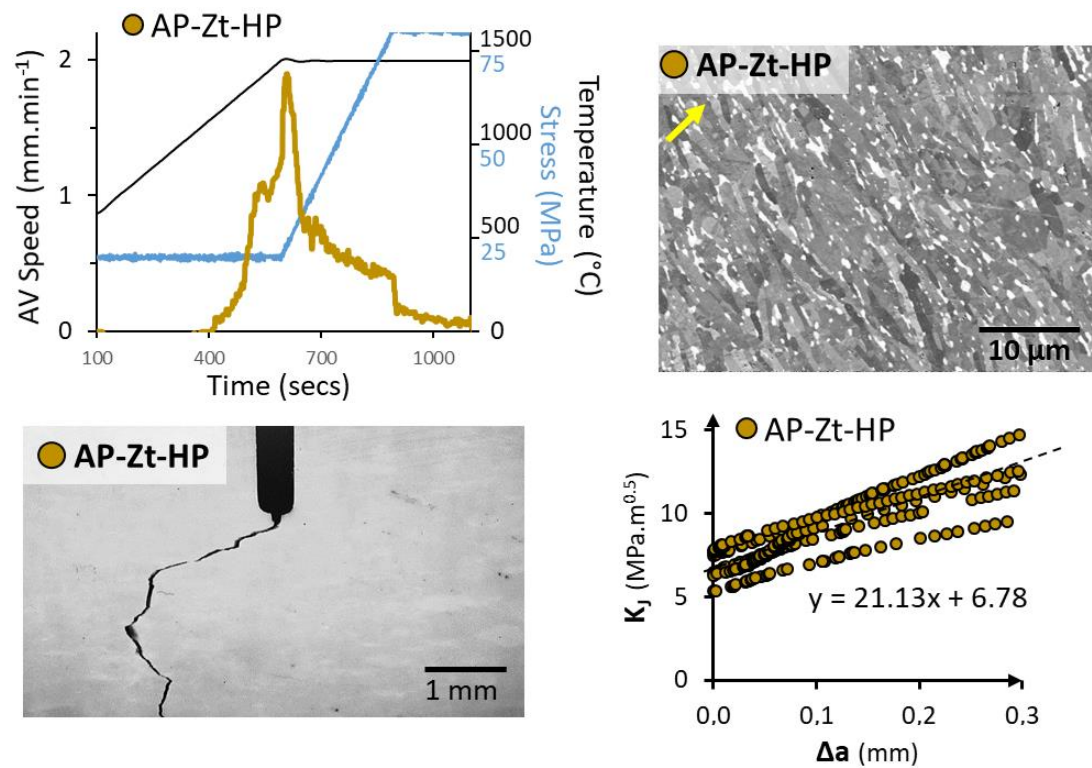

Figure 9 : Densification curve, microstructure, crack deviation and R-curves of the AP-Zt-HP sample, sintered with a maximum pressure of $80 \mathrm{MPa}$. (C) (2021) R. Henry et al. (10.6084/m9.figshare.14994159) CC BY 4.0 license https://creativecommons.org/licenses/by/4.0/.

\section{Discussion}

\subsection{Influence of glass phase and alumina nanoparticles on microstructure and properties of nacre-like composites}

Densification begins earlier and is more pronounced in the presence of glass phase and alumina nanoparticles in the composition (FIGURE 5 and TABLE 1). Indeed, samples without glass phase and alumina nanoparticles (AP samples) shows a lower relative density (between $92 \%$ and $95 \%$ ) as compared to $A P^{n g}$ samples (between $96 \%$ and $97 \%$ ). In contrast, for the AP-Zt-HP sample, sintered at a pressure of $80 \mathrm{MPa}$, the density is close to that of samples with glass phase and nanoparticles. This seems to show that the glass phase and the alumina nanoparticles act as an aid to densification.

All samples show a typical anisotropic nacre-like microstructure (FIGURE 7). The relatively direct shaping process used allows the desired microstructure to be obtained by simple FAST, with the orientation of the platelets being initiated during powder pressing [12]. The use of glass phase and alumina nanoparticles plays a role in slowing down the grain growth during sintering, which helps to maintain the dimensions of the alumina platelets and thus to have a fine microstructure in the composite [10]. However, in the context of this work, it is clear that a fine and dense microstructure, i.e. a low grain growth of the platelets, can be obtained using neither a glassy phase nor nanoparticles, as already shown by Evers et al. [11].

The morphology of the cracks during bending of a notched bar does not seem to be particularly affected by the presence of nanoparticles or glass phase in the composition (FIGURE 7). The crack always follows the interfaces between the alumina platelets. The presence of the glass phase and nanoparticles however increases the reinforcement noted on the force-displacement curves (FIGURE 3 ) and improves the mechanical properties (FIGURE 4 and FIGURE 8). This is probably first explained by the reduction of porosity during sintering. This hypothesis is further supported by the better properties of AP-Zt-HP compared to AP-Zt; the higher maximum pressure during the sintering increases the final relative density and the fracture properties of the material, as shown in FIGURE 10. It should be noted, however, that between $A P^{n g}-Z t$ and AP-Zt-HP, the strength is higher for $A P^{n g}-Z t$ despite similar porosity. The glass phase and the nanoparticles therefore tend to improve the fracture properties of the material, certainly by reducing the porosity, but not only. They could also improve the sintering quality possibly resulting in a better adhesion between alumina platelets. 


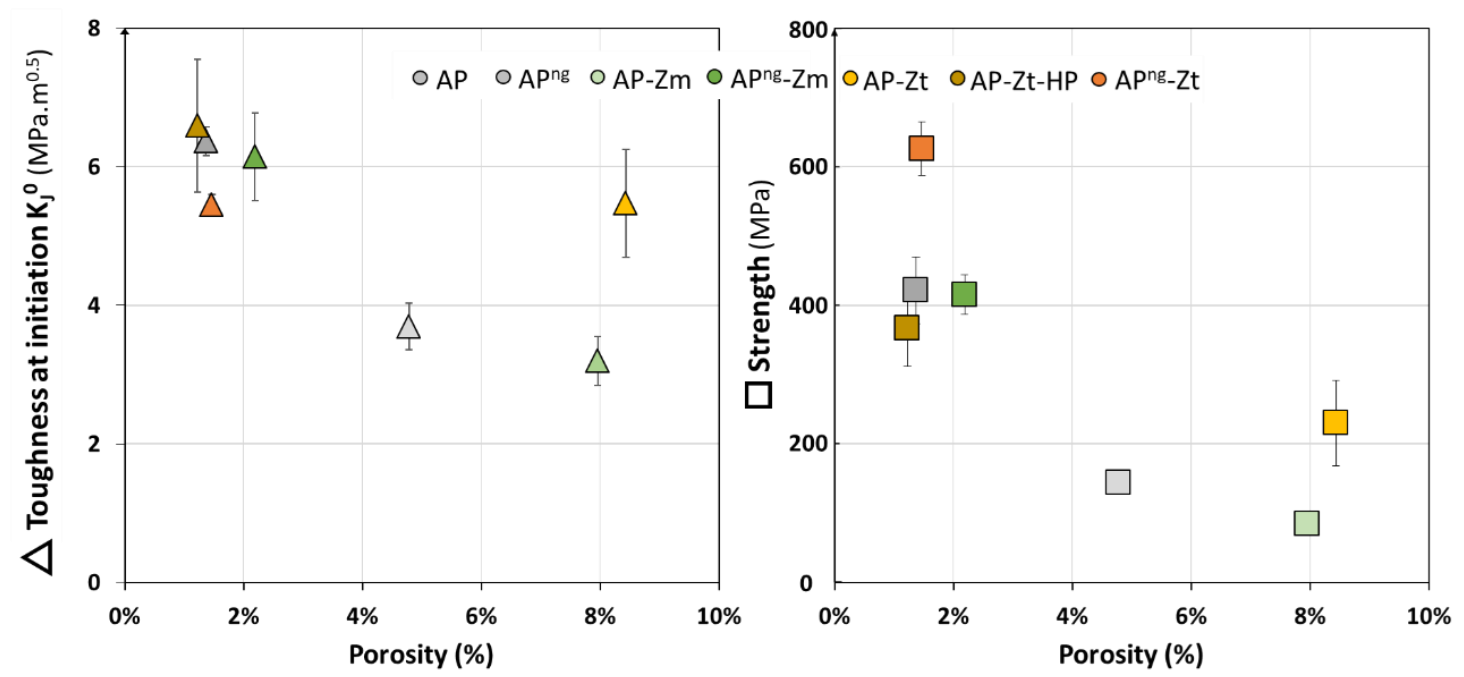

Figure 10 : Fracture properties of samples as a function of their porosity. (c) (2021) R. Henry et al. (10.6084/m9.figshare.14994159) CC BY 4.0 license https://creativecommons.org/licenses/by/4.0/.

\subsection{Influence of zirconia on microstructure and properties of nacre-like composites}

The presence of zirconia, whether introduced chemically as a precursor $(Z m)$ or by powder adsorption $(Z t)$, has only a moderate influence on the final density or on the densification curve of the samples (TABLE 1 and FIGURE 5). On the other hand, the presence of 10 vol\% of zirconia seems to slow grain growth. The alumina platelets of the AP sample appear coarser than the platelets of the AP-Zm and AP-Zt samples (FIGURE 6), which were sintered under the same conditions, i.e. up to $1450^{\circ} \mathrm{C}$, up to $40 \mathrm{MPa}$ and without glass phase (FIGURE 9). In addition, the AP-Zt- HP sample was sintered at $1450^{\circ} \mathrm{C}$ and $80 \mathrm{MPa}$ and does not show a coarser microstructure, yet for similar sintering conditions and without zirconia, coarser grains have already been observed [11].

In the context of this work, chemically introduced zirconia $\left(A P^{n g}-Z m\right)$ tends to remain in the monoclinic phase (FIGURE 2), while in the literature, for isotropic zirconia toughened alumina prepared from spherical alumina powders, chemically introduced zirconia can remain in the tetragonal phase at room temperature after sintering, even without stabilizer, in particular because the zirconia particles can be kept below the critical size for stabilization [5]. Using XRD (FIGURE 2), the AP-Zm sample shows no peak related to the tetragonal phase, while the $A P^{n g}-Z m$ sample shows only a small tetragonal peak. On the other hand, the $Z t$ samples clearly show much more developed tetragonal peaks: $A P$-Zt shows a tetragonal peak that is much larger than the monoclinic peak and the $A P^{n g}-Z t$ and $A P-Z t-H P$ samples show only tetragonal peaks and no monoclinic peaks. It appears that a stabilizer, here $\mathrm{Y}_{2} \mathrm{O}_{3}$, is required to keep the zirconia in the tetragonal phase at room temperature. It also shows that the presence of glass phase and alumina nanoparticles results in less monoclinic phase than the homologous sample without these additives. The same trend is observed for the sample sintered at $80 \mathrm{MPa}$ instead of $40 \mathrm{MPa}$. It therefore appears that when sintering is more advanced it can help to stabilize the zirconia in the tetragonal phase. This difference with literature [5] may possibly be related to the size and shape of the alumina grains, which are relatively large but also elongated (platelets) in the present work. This geometry of alumina platelets leads proportionally to less interface between grains on which zirconia can disperse after sintering, which logically leads to larger zirconia clusters at the triple grain boundaries.

In this work, it is shown that the addition of zirconia does not hinder the establishment of a nacre-like microstructure (FIGURE 6) using only FAST for platelets orientation, even when there is no glass phase or nanoparticles. After introduction of zirconia either by chemical route $(\mathrm{Zm})$ or by powder adsorption onto the platelets $(Z t)$, zirconia is homogeneously localized between the alumina grains. Zirconia in the monoclinic phase does not improve the mechanical properties, with $Z m$ samples having properties close and slightly below those of samples without zirconia (AP) (FIGURE 4). This could be explained by a slight decrease in the density of samples with Zm zirconia compared to AP samples (FIGURE 10). On the other hand, zirconia in tetragonal form seems to be beneficial for the fracture properties of the material. Indeed, the strength of $A P^{n g}-Z t$ is $50 \%$ higher than that 
of $A P^{n g}$, while the strength and toughness of $A P-Z t$ and especially $A P-Z t-H P$ are clearly above that of $A P$. It is also noted that the mechanical properties follow a trend with the porosity fraction (they decrease with the porosity fraction up to $10 \%$ (FIGURE 10)).

In literature, alumina-zirconia composites have been extensively studied, and it is recognized that the addition of zirconia can be beneficial in terms of mechanical properties. Depending on the phase in which the zirconia is, the particle size or the presence or absence of stabilizer for the tetragonal phase, different strengthening mechanisms can be involved, such as stress-induced phase transformation [19], interaction of cracks with microcracks in the zirconia [2] or residual stresses induced by differential thermal expansion between zirconia and alumina [20]. In this work, we note a strengthening with zirconia, but only when it is in the tetragonal phase. For the $Z t$ samples, the increase in property is visible only for the strength, the toughness (at initiation or in Rcurves) not seeming to be affected. The strengthening by phase transformation being supposed to act on the Rcurve of the sample, we can assume here that this effect is minor and probably erased by the strengthening induced by the crack deflection. Finally, the introduction of residual stresses induced by the difference of thermal expansion between zirconia and alumina (respectively $7.2 \times 10^{-6} \mathrm{~K}^{-1}$ and $7.2 \times 10^{-6} \mathrm{~K}^{-1}$ [16]) may play an important role in the observed increase in strength of samples [5].

\subsection{Crack propagation and damage resistance}

In this work, we have shown that all samples show crack deviation in SENB tests, whether they have a glass phase or not (FIGURE 3). Crack propagation is therefore controlled by the interfaces between the alumina platelets, whether the interface contains or not a glass phase (FIGURE 7). When studying the R-curves of the different samples (FIGURE 8), at first glance the slope of the curves, i.e. the evolution of their toughness with the depth of the crack, differs according to the sample. This is potentially an effect of the difference in composition and therefore of the presence of glass or zirconia at the interfaces between the platelets.

However, these slope coefficients actually appear to follow the trend of the toughness at crack initiation $K_{J}^{0}$ (approximately 4 times $K_{\lrcorner}^{0}$, using the units of FIGURE 8 ). Intuitively one expects the slope of the curve $K_{\lrcorner}^{0}=f(\Delta a$ ) to be related to the crack propagation resistance property of the specimen. In our case, it is the interface strength that drives fracture initiation and potentially also the crack propagation, hence the proportionality between these two parameters. It would be beneficial to study this observation in more detail, in particular to determine what is part attributable to the different reinforcement mechanisms potentially present (zirconia phase change, friction and sliding of the platelets...).

To quantify the quality of the interface between platelets for different composition, it would be necessary to be able to carry out crack tests only in opening mode $I$, either by making large samples (to open the interfaces in bending or using wedge testing) or by carrying out micromechanical tests [14]. Indeed, the capability of nacrelike alumina to deflect the cracks initiated from a notch is beneficial to its crack propagation resistance, it does not prevent brittle fracture on specimens without notches, these samples showing a linear elastic behaviour up to failure.

\subsection{Comparison with previous nacre-like alumina studies}

All the fracture properties of the specimens, i.e. initiation toughness and strength, are plotted in a graph that brings together the different nacre-like alumina composites found in the literature [9] (FIGURE 11).

First of all, we note that the $A P^{n g}$ sample, of similar composition to that of [12] and [10], has slightly higher strength because the tested volume of the samples in this study is smaller and is therefore probably due to a statistical effect. It can be noted that the samples without glass phase and alumina nanoparticles, although easier to process, have rather weak properties.

It is interesting to note that the samples with tetragonal zirconia $A P-Z t$ and $A P-Z t-H P$ are attractive in terms of properties, even without the presence of glass phase or alumina nanoparticles. $A P-Z t$ has much weaker properties than the standard $A P^{n g}$ composition, probably because of its high porosity. The application of a higher sintering stress $(A P-Z t-H P)$ reduces the porosity and finally leads to properties quite close to $A P^{n g}$. This composition has the advantage of simpler shaping, because without addition of nanoparticles and glass phase, 
and is potentially more resistant to creep because without glass at the grain boundaries, creep being a critical issue for high temperature applications.

Finally, the combination of glass phase and alumina nanoparticles with zirconia particles in tetragonal phase allows to obtain high properties for nacre-like materials. It leads to the highest properties, similar to those of the two best compositions referenced in the literature, namely a nacre-like alumina using a glassy phase and alumina nanoparticles as mortar [21] and a nacre-like alumina using aluminium borate as secondary phase [15], both prepared by a MASC (Magnetically Assisted Slip Casting) process.

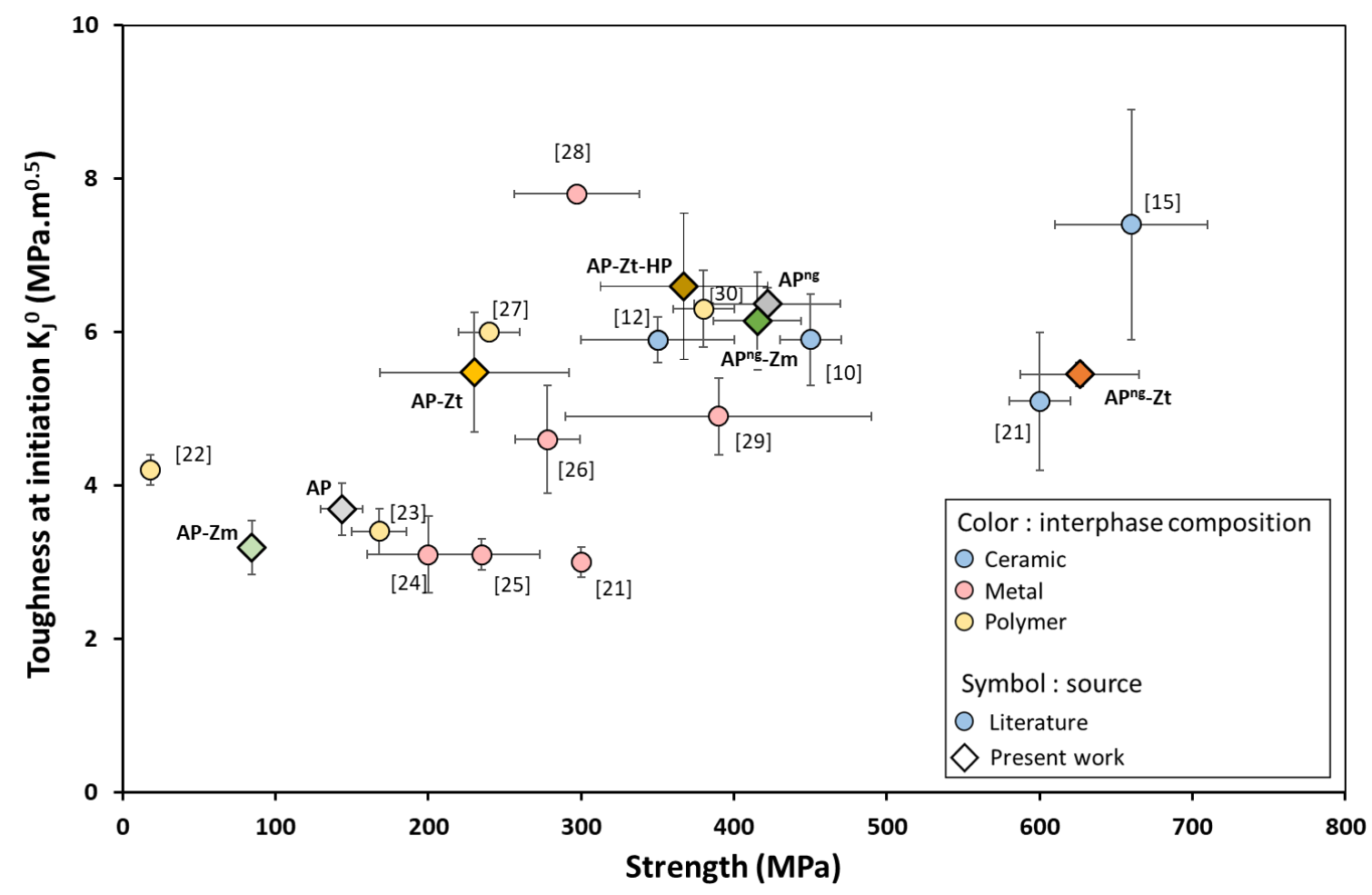

Figure 11 : Toughness at crack initiation $K_{\lrcorner}^{0}$ as a function of bending strength of nacre-like alumina composites made with different mortar compositions. (Literature data [10], [15], [21]-[30] are taken from [9]). (C) (2021) R. Henry et al. (10.6084/m9.figshare.14994159) CC BY 4.0 license https://creativecommons.org/licenses/by/4.0/.

\section{Conclusions}

Nacre-like composites were prepared from alumina platelets with a relatively simple process. Different compositions were tested, with and without a glass phase and alumina nanoparticles and with zirconia particles in monoclinic phase or stabilised in tetragonal phase. The direct use of FAST makes it possible to obtain a microstructure with the platelets oriented in a preferential direction. This anisotropy allows crack deviation to be generated in the tested specimens.

The mechanical characterisation of all these composites shows that the reinforcement noted in R-curves is mainly driven by crack deflection along the platelet interfaces. The presence of glass or zirconia at the grain boundaries does not significantly influence this behaviour.

Glass and nanoparticles, generally introduced to generate a weaker phase through which the crack propagates, seems to be mainly useful for improving the densification of the material, as the cracks are deflected even when the composite does not have this secondary phase.

It has been shown that addition of zirconia is only beneficial for the mechanical properties when zirconia is in tetragonal phase, and that this phase is only present if stabilized zirconia is introduced (with $\mathrm{Y}_{2} \mathrm{O}_{3}$ here). When zirconia is in the tetragonal phase, it increases the strength of the material and slow down the growth of alumina grains during sintering. The composition of alumina platelets with tetragonal zirconia gives promising results in terms of fracture properties, and the absence of a glass phase makes it a potential candidate for higher 
temperature applications, where creep resistance, for example, is often a critical property. Finally, the combination of glass, alumina nanoparticles and tetragonal zirconia allows to reach values of toughness at initiation and strength close to the best nacre-like alumina referenced in the literature but using a simpler shaping process.

\section{Acknowledgments}

We are grateful for the financial support from the Agence Nationale pour la Recherche (ANR-16-CE08-0006 BICUIT, program DS0303-2016). We would like to thank Florian Mercier (MATEIS) for its help with the FAST press. The CLYM (www.clym.fr) is also thanked for access to microscopes. 


\section{Bibliography}

[1] D. Munz and T. Fett, Ceramics, Springer. 1999.

[2] N. Claussen, "Fracture Toughness of Al2O3 with an Unstabilized ZrO2 Dispersed Phase," J. Am. Ceram. Soc., vol. 59, no. 1-2, pp. 49-51, 1976, doi: 10.1111/j.1151-2916.1976.tb09386.x.

[3] N. Claussen, "Stress-induced Transformation of Tetragonal ZrO2 Particles in Ceramic Matrices," J. Am. Ceram. Soc., vol. 61, no. 1-2, pp. 85-86, 1978, doi: 10.1080/00029890.1944.11999053.

[4] A. H. De Aza, J. Chevalier, G. Fantozzi, M. Schehl, and R. Torrecillas, "Crack growth resistance of alumina, zirconia and zirconia toughened alumina ceramics for joint prostheses," Biomaterials, vol. 23, no. 3, pp. 937-945, 2002, doi: 10.1016/S0142-9612(01)00206-X.

[5] M. Schehl, L. A. Díaz, and R. Torrecillas, "Alumina nanocomposites from powder-alkoxide mixtures," Acta Mater., vol. 50, no. 5, pp. 1125-1139, 2002, doi: 10.1016/S1359-6454(01)00413-X.

[6] R. H. J. Hannink, P. M. Kelly, and B. C. Muddle, "Transformation toughening in zirconia-containing ceramics," J. Am. Ceram. Soc., vol. 83, no. 3, pp. 461-487, 2000, doi: 10.1111/j.11512916.2000.tb01221.x.

[7] I. Corni, T. J. Harvey, J. A. Wharton, K. R. Stokes, F. C. Walsh, and R. J. K. Wood, "A review of experimental techniques to produce a nacre-like structure," Bioinspiration and Biomimetics, vol. 7, no. 3, 2012, doi: 10.1088/1748-3182/7/3/031001.

[8] F. Barthelat, H. Tang, P. D. Zavattieri, C. M. Li, and H. D. Espinosa, “On the mechanics of mother-ofpearl: A key feature in the material hierarchical structure," J. Mech. Phys. Solids, vol. 55, no. 2, pp. 306$337,2007$.

[9] F. Bouville, "Strong and tough nacre-like aluminas: Process-structure-performance relationships and position within the nacre-inspired composite landscape," J. Mater. Res., pp. 1-19, 2020.

[10] F. Bouville, E. Maire, S. Meille, B. Van De Moortèle, A. J. Stevenson, and S. Deville, "Strong, tough and stiff bioinspired ceramics from brittle constituents," Nat. Mater., vol. 13, no. 5, pp. 508-514, 2014.

[11] K. Evers, S. Falco, N. Grobert, and R. I. Todd, "Nacre-like alumina with unique high strain rate capabilities," J. Eur. Ceram. Soc., vol. 40, no. 2, pp. 417-426, 2020, [Online]. Available: https://doi.org/10.1016/j.jeurceramsoc.2019.09.015.

[12] H. Saad et al., "A simple approach to bulk bioinspired tough ceramics," Materialia, vol. 12, no. 100807, 2020, doi: https://doi.org/10.1016/j.mtla.2020.100807.

[13] K. Radi, D. Jauffrès, S. Deville, and C. L. Martin, "Elasticity and fracture of brick and mortar materials using discrete element simulations," J. Mech. Phys. Solids, vol. 126, pp. 101-116, 2019, [Online]. Available: https://doi.org/10.1016/j.jmps.2019.02.009.

[14] R. Henry, H. Saad, A. Doitrand, S. Deville, and S. Meille, "Interface failure in nacre-like alumina," J. Eur. Ceram. Soc., vol. 40, no. 13, pp. 4694-4699, 2020, doi: 10.1016/j.jeurceramsoc.2020.05.068.

[15] P. Pelissari et al., "Nacre-like ceramic refractories for high temperature applications," J. Eur. Ceram. Soc., vol. 38, no. 4, pp. 2186-2193, 2018.

[16] M. J. Marcinkowska, "Elaboration and characterization of mechanical properties of ceramic composites with controlled architecture," PhD Thesis, Insa Lyon, p. 139, 2018.

[17] H. Toraya, M. Yoshimura, and S. Somiya, "Calibration Curve for Quantitative Analysis of the MonoclinicTetragonal ZrO2 System by X-Ray Diffraction," J. Am. Ceram. Soc., vol. 67, no. 6, p. C-119-C-121, 1984, doi: 10.1111/j.1151-2916.1984.tb19715.x.

[18] ASTM Standard, “E1820: Measurement of Fracture Toughness," 2003.

[19] Shin, Yu Seon, Y. W. Rhee, and S. J. L. Kang, “Experimental evaluation of toughening mechanisms in alumina-zirconia composites," J. Am. Ceram. Soc., vol. 82, no. 5, pp. 1229-1232, 1999, doi: 


\subsection{1/j.1151-2916.1999.tb01900.x.}

[20] M. Szutkowska, "Fracture resistance behavior of alumina-zirconia composites," J. Mater. Process. Technol., vol. 153-154, no. 1-3, pp. 868-874, 2004, doi: 10.1016/j.jmatprotec.2004.04.406.

[21] H. Le Ferrand, F. Bouville, T. P. Niebel, and A. R. Studart, "Magnetically assisted slip casting of bioinspired heterogeneous composites," Nat. Mater., vol. 14, no. 11, pp. 1172-1179, 2015.

[22] A. Wat et al., "Bioinspired nacre-like alumina with a bulk-metallic glass-forming alloy as a compliant phase," Nat. Commun., vol. 10, no. 1, pp. 1-12, 2019, doi: 10.1038/s41467-019-08753-6.

[23] M. Grossman, F. Bouville, F. Erni, K. Masania, R. Libanori, and A. R. Studart, "Mineral NanoInterconnectivity Stiffens and Toughens Nacre-like Composite Materials," Adv. Mater., vol. 29, no. 8, 2017, doi: 10.1002/adma.201605039.

[24] S. Askarinejad and N. Rahbar, "Mechanics of bioinspired lamellar structured ceramic/polymer composites: Experiments and models," Int. J. Plast., vol. 107, no. April, pp. 122-149, 2018, doi: 10.1016/j.ijplas.2018.04.001.

[25] T. P. Niebel, F. Bouville, D. Kokkinis, and A. R. Studart, "Role of the polymer phase in the mechanics of nacre-like composites," J. Mech. Phys. Solids, vol. 96, pp. 133-146, 2016, doi: 10.1016/j.jmps.2016.06.011.

[26] R. P. Wilkerson, B. Gludovatz, J. Watts, A. P. Tomsia, G. E. Hilmas, and R. O. Ritchie, "A Novel Approach to Developing Biomimetic ('Nacre-Like') Metal-Compliant-Phase (Nickel-Alumina) Ceramics through Coextrusion," Adv. Mater., vol. 28, no. 45, pp. 10061-10067, 2016, doi: 10.1002/adma.201602471.

[27] J. Huang, W. S. Rubink, H. Lide, T. W. Scharf, R. Banerjee, and M. Minary-Jolandan, "Alumina-Nickel Composite Processed via Co-Assembly Using Freeze-Casting and Spark Plasma Sintering," Adv. Eng. Mater., vol. 21, no. 3, pp. 1-8, 2019, doi: 10.1002/adem.201801103.

[28] J. Huang, S. Daryadel, and M. Minary-Jolandan, "Low-Cost Manufacturing of Metal-Ceramic Composites through Electrodeposition of Metal into Ceramic Scaffold," ACS Appl. Mater. Interfaces, vol. 11, no. 4, pp. 4364-4372, 2019, doi: 10.1021/acsami.8b18730.

[29] G. Dwivedi, K. Flynn, M. Resnick, S. Sampath, and A. Gouldstone, "Bioinspired hybrid materials from spray-formed ceramic templates," Adv. Mater., vol. 27, no. 19, pp. 3073-3078, 2015, doi: 10.1002/adma.201500303.

[30] A. Wat et al., "Bioinspired Nacre-Like Alumina with a Metallic Nickel Compliant Phase Fabricated by Spark-Plasma Sintering," Small, vol. 15, no. 31, pp. 1-7, 2019, doi: 10.1002/smll.201900573. 